\title{
Are Growing Pains Related to Vitamin D Deficiency? Efficacy of Vitamin D Therapy for Resolution of Symptoms
}

\author{
Aysel Vehapoglu ${ }^{a} \quad$ Ozden Turel $^{a}$ Serdar Turkmen ${ }^{b}$ Berrin Belcik Inal ${ }^{c}$ \\ Turgut Aksoyc Gamze Ozgurhan ${ }^{\mathrm{d}}$ Murat Ersoy ${ }^{\mathrm{c}}$ \\ ${ }^{a}$ Department of Pediatrics, Bezmialem Vakıf University School of Medicine, ${ }^{b}$ Department of Biochemistry, Bakirkoy \\ Sadi Konuk Training and Research Hospital, ' Department of Biochemistry, Istanbul Training and Research Hospital, \\ and d Department of Pediatrics, Suleymaniye Obstetrics and Gynecology Hospital, Istanbul, Turkey
}

\section{Key Words}

Growing pains $\cdot$ Vitamin D $\cdot$ Visual analog scale $\cdot$ Children

\begin{abstract}
Objectives: The aim of this study was to investigate the 25 -hydroxyvitamin $D[25(\mathrm{OH}) \mathrm{D}]$ status of children with growing pains and to evaluate the efficacy of vitamin $D$ treatment on the resolution of pain symptoms. Subjects and Methods: One hundred and twenty children with growing pains were included in a prospective cohort study. Serum $25(\mathrm{OH}) \mathrm{D}$ and bone mineral levels were measured in all subjects at the time of enrollment. The pain intensity of those with vitamin D deficiency was measured using a pain visual analog scale (VAS). After a single oral dose of vitamin $D$, the pain intensity was remeasured by means of the VAS at 3 months. The 25(OH)D levels and VAS scores before and after oral vitamin $\mathrm{D}$ administration were compared by means of a paired Student's t test. Results: In the 120 children with growing pains, vitamin $D$ insufficiency was noted in 104 (86.6\%). Following vitamin D supplementation, the mean $25(\mathrm{OH}) \mathrm{D}$ levels increased from $13.4 \pm 7.2$ to $44.5 \pm$ $16.4 \mathrm{ng} / \mathrm{ml}$, the mean pain VAS score decreased from $6.8 \pm$ 1.9 to $2.9 \pm 2.5 \mathrm{~cm}$ (a mean reduction of $-3.8 \pm 2.1, \mathrm{p}<0.001$ )
\end{abstract}

and the difference was statistically significant. Conclusion: Supplementation with oral vitamin D resulted in a significant reduction in pain intensity among these children with growing pains who had hypovitaminosis $\mathrm{D}$.

(c) 2015 S. Karger AG, Basel

\section{Introduction}

Growing pains are the most common form of nonspecific, recurrent leg pains in childhood, and are frequent causes for pediatric outpatient visits. The estimated prevalence of growing pains worldwide ranges from 3 to $37 \%$ $[1,2]$. Growing pains are familial and mainly affect children aged 4-12 years, and are most prevalent in those aged 4-6 years [3]. Such pain usually occurs in the evening or during the night, but never in the morning. It may awaken the child from sleep, and the intensity can be so severe that it can make the child cry. It is typically nonarticular, intermittent, bilateral and not associated with limited mobility. It is located in the muscles and predominantly affects the anterior thighs, shins, calves or backs of the knees [4]. The pain can be precipitated by exercise and lasts from minutes to hours. Physical examination

\begin{tabular}{ll}
\hline KARGER 125/s & $\begin{array}{l}\text { ○ 2015 S. Karger AG, Basel } \\
1011-7571 / 15 / 0244-0332 \$ 39.50 / 0 \quad \text { Karger }\end{array}$ \\
E-Mail karger@karger.com & $\begin{array}{l}\text { This is an Open Access article licensed under the terms of the } \\
\text { Creative Commons Attribution-NonCommercial 3.0 Un- } \\
\text { ported license (CC BY-NC) (www.karger.com/OA-license), } \\
\text { applicable to the online version of the article only. Distribu- } \\
\text { tion permitted for non-commercial purposes only. }\end{array}$
\end{tabular}

Aysel Vehapoglu

Department of Pediatrics, Bezmialem Vakıf University, School of Medicine

Vatan Street, Fatih

TR-34093 Istanbul (Turkey)

E-Mail ayvahap@ hotmail.com 
does not reveal objective signs of inflammation, and laboratory test results are generally normal [5]. Growing pains do not progress to organic disease and usually resolve by adolescence [6]. Although the term 'growing pains' has been used for more than 190 years in the medical literature, the cause of and optimal treatment for such pains remain unknown. An interesting approach would be to consider calcium and vitamin $\mathrm{D}$ metabolism because adequate dietary intake of these nutrients is important to maintain normal bone mineralization and muscle function [7].

Vitamin D is an essential component of bone and mineral metabolism. It is required to accelerate calcium absorption in the intestine and is essential for normal growth-plate calcification and bone mineralization. It plays a significant role in the homeostasis of calcium and phosphorus and is vital for bone mineralization, skeletal growth and bone health. A normal vitamin D status seems to be protective against musculoskeletal disorders (muscle weakness, falls and fractures), infectious disease, autoimmune disease, cardiovascular disease, types 1 and 2 diabetes mellitus, several types of cancer, neurocognitive dysfunction and mental illness $[8,9]$. An association between the vitamin $\mathrm{D}$ level and chronic pain conditions has been described in adults; the patients' pain condition improved with vitamin D supplementation $[10,11]$. Turkey receives a high level of sunlight, and vitamin D deficiency was thus thought to be unusual here; however, the reported prevalence of hypovitaminosis D is $40-65 \%$ in this country $[12,13]$. In this study, we assessed the serum 25 -hydroxyvitamin D [25(OH)D] level in children with growing pains and investigated whether limb pain improved with vitamin D supplementation. We hypothesized that calcium enrichment and vitamin D supplementation might affect the bone and muscle status and decrease both the rate and intensity of pain in children with growing pains.

\section{Subjects and Methods}

A prospective cohort study was carried out at the Bezmialem Vakif University Hospital in Istanbul among children who attended the outpatient clinics from October 2013 to March 2014. The study protocol was carried out in accordance with the Helsinki Declaration as revised in 1989. Information about the aim of the study was explained to the children's parents at the time of enrollment, and their written informed consent was obtained. The Research Ethics Committee of the University approved the study. In total, 148 children aged 4-12 years with growing pains were identified. Sixteen children dropped out of the study during the followup: 2 had hypocalcemia and 14 [4 years old $(n=10), 5$ years old $(n=3)$ and 6 years old $(n=1)]$ were unable to use the VAS at the second visit. Twelve children were lost to follow-up. Hence, the study group included 120 children (52 boys and 68 girls) with growing pains, characterized by recurrent limb pain that lasted $>6$ months according to the criteria of Evans [6]. The inclusion criteria for a diagnosis of growing pains were: (1) if the children experienced intermittent (nonarticular) pains in both legs, generally occurring late in the day or at night and not associated with limping or limited mobility and (2) the children had to have adequate cognitive and physical development for understanding the VAS. Exclusion criteria were (1) if the children had persistent pain, increasingly intense pain at night that was still present the following morning and joint pain and (2) if they had organic causes of pain or signs of inflammation such as local tenderness or swelling, underlying illnesses such as rickets, malnutrition, rheumatologic disorders, celiac disease or systemic illness or were taking vitamin or mineral supplements. The study group represented a relatively light-skinned pediatric population living in an industrialized sunny area in Istanbul at a latitude of $41^{\circ} \mathrm{N}$. Skin pigmentation was classified according to the Fitzpatrick phototyping scale with types ranging from I to VI [14]. All subjects underwent a complete physical examination. At the clinical visits, height and weight were measured using a standard stadiometer and a digital scale, respectively. The body mass index (BMI) was then calculated for all subjects. Initially, all of them underwent evaluation of a complete blood cell count, the erythrocyte sedimentation rate and levels of serum total calcium, phosphate, alkaline phosphatase (ALP), serum $25(\mathrm{OH}) \mathrm{D}$, creatinine kinase, C-reactive protein and parathyroid hormone $(\mathrm{PTH})$.

Venous blood samples were taken in the morning following a 12-hour overnight fast. The serum 25(OH)D level was measured using an electrochemiluminescence enzyme immunoassay method (ADVIA Centaur; USADPC Co., USA). Vitamin D deficiency was defined as a $25(\mathrm{OH}) \mathrm{D}$ serum concentration of $\leq 10 \mathrm{ng} / \mathrm{ml}(25$ $\mathrm{nmol} / \mathrm{l})$. A level of $10-20 \mathrm{ng} / \mathrm{ml}(25-50 \mathrm{nmol} / \mathrm{l})$ was defined as vitamin D insufficiency, whereas a level of $\geq 20 \mathrm{ng} / \mathrm{ml}$ was considered sufficient/optimal $[15,16]$.

Those identified as having vitamin D deficiency were evaluated for pain intensity using a pain VAS at the beginning. The VAS measurement was repeated at 3 months because there was no homogeneity in pain frequency amongst the children. After 1 month of vitamin D treatment, the children underwent measurement of serum vitamin $\mathrm{D}$, calcium, $\mathrm{PTH}$ and urine calcium/creatinine levels, in order to check if the vitamin D dose had been effective and to monitor side effects such as hypercalcemia.

Pain severity after 3 months of vitamin D therapy was evaluated using a VAS consisting of a linear scale (a horizontal line 100 $\mathrm{mm}$ long). The number of centimeters marked was recorded as a score from 0 to 10 : no pain $=0$, moderate pain $=5$ and very severe pain that was intense enough to make the child cry $=10$. Children and their families were taught in detail how to use the VAS. The children were asked to mark the level of pain they experienced during the most recent attack. Those with vitamin D deficiency were given a single oral dose of vitamin D $[150,000 \mathrm{IU}$ ( $\leq 6$ years of age) or 300,000 IU ( $>6$ years of age)] and oral calcium supplementation $(1,000 \mathrm{mg} /$ day $)$ for $1 \mathrm{month}$. The change in pain intensity was calculated.

Version 15 of the Statistical Package for the Social Sciences (SPSS) statistical program for Windows (SPSS Inc., Chicago, Ill., USA) was used for the statistical analysis. Numerical parameters 
are presented as means and standard deviations, and the distributions of categorical measurements are presented as frequencies and percentages. The 25(OH)D levels and VAS scores before and after oral vitamin $\mathrm{D}$ administration were compared with a paired Student's t test. Relationships of mean differences were evaluated by Pearson's correlation analysis. Categorical data were compared by means of the $\chi^{2}$ test. A $p$ value of $<0.05$ was accepted as indicative of statistical significance.

\section{Results}

Vitamin D insufficiency $(<20 \mathrm{ng} / \mathrm{ml})$ was detected in 104 of $120(86.6 \%)$ children at the baseline of the study; $25.0 \%$ of them had a deficiency $(\leq 10 \mathrm{ng} / \mathrm{ml})$. The $25(\mathrm{OH})$ $\mathrm{D}$ levels at baseline did not correlate with the clinical characteristics of children with growing pains, with the exception of skin color. Dark-skinned children were more likely to have vitamin $\mathrm{D}$ deficiency than fair-skinned children. The mean $25(\mathrm{OH}) \mathrm{D}$ levels of children with dark and fair skin were $11.8 \pm 5.6$ and $15.6 \pm 8.4 \mathrm{ng} / \mathrm{ml}$, respectively $(\mathrm{p}<0.05)$. There was no correlation between the basal serum 25(OH)D levels and the BMI z-score. Of 120 children with growing pains, $6(5 \%)$ had serum PTH levels of $>74.9 \mathrm{mg} / \mathrm{dl}$ (mean $37.5 \pm 17.0 \mathrm{mg} / \mathrm{dl}$ ). The PTH level was negatively correlated with the basal $25(\mathrm{OH}) \mathrm{D}$ level $(\mathrm{r}=-0.42, \mathrm{p}<0.001)$. The ALP levels were elevated in 5 children $(269.0 \mathrm{mg} / \mathrm{dl}$ in 2 children $4-6$ years of age and $>300.0 \mathrm{mg} / \mathrm{dl}$ in 3 children $6-12$ years of age; mean $203.6 \pm 58.1 \mathrm{mg} / \mathrm{dl}$ ).

The demographic characteristics of the study population are presented in table 1 . Of the 120 children with growing pains, $21(17.5 \%)$ had pain during the afternoon, $51(42.5 \%)$ in the evening and $48(40.0 \%)$ at night. The frequency of pain was once per week in 28 (23.3\%) children, twice per week in 37 (30.8\%), 3-4 times per week in $25(20.9 \%)$, every day in $14(11.7 \%)$ and once per month in $16(13.3 \%)$. Pain localization was at the anterior thigh in $10(8.3 \%)$, in the knee and thigh in $12(10.0 \%)$, in the popliteal fossa and knee in $35(29.2 \%)$, in the shin and knee in 23 (19.1\%), in the calf and shin in $32(26.7 \%)$ and in the arm and leg in $8(6.7 \%)$. Limbs on the left and right were involved in 105 (87.5\%) of the children. Pain caused waking from sleep and crying episodes in 57 (48\%) and 41 (34\%) children, respectively. A total of 95 (79.1\%) children stated that their pain was relieved by massage and 74 $(61.6 \%)$ said that they frequently required analgesics. Four (34.2\%) children had a family history of growing pain. In 32 (26.6\%) children, abdominal pain was accompanied by limb pains, and $36(30.0 \%)$ had concurrent headaches. In $59(49.1 \%)$ children, the growing pains
Table 1. Comparison of demographic and clinical characteristics of children with growing pains

$\begin{array}{lc}\text { Total number of children } & 120 \\ \text { Gender } & \\ \quad \text { Female } & 68(56.6) \\ \quad \text { Male } & 52(43.4) \\ \text { Age, years } & 7.8 \pm 2.6(4-12) \\ \text { Weight, kg } & 26.2 \pm 8.5(14-48) \\ \text { Weight, percentile } & 43.3 \pm 30 \\ \text { Height, cm } & 124.7 \pm 14.6(98-157) \\ \text { Height, percentile } & 39.8 \pm 28.2 \\ \text { BMI } & 16.5 \pm 2.3(11.7-23.4) \\ \text { BMI z-score } & -0.06 \pm 1.2(-3.9 \text { to } 2.9) \\ \text { 25(OH)D, ng/ml } & 13.4 \pm 7.2(<4-54.4)\end{array}$

The data are expressed as $\mathrm{n}(\%)$ or mean $\pm \mathrm{SD}$ (range).

were associated with daily physical activity, and 54 (45\%) experienced pains in the summer months. Physical examination revealed that $70(58.4 \%)$ children with growing pains were dark-skinned (Fitzpatrick phototype IIIIV) and that 50 (41.6\%) were fair (type II). None of the children was classified as type I, V or VI.

The serum level of $25(\mathrm{OH}) \mathrm{D}$ in the children with growing pains and vitamin $\mathrm{D}$ deficiency increased after 1 month of vitamin D therapy from $13.4 \pm 7.2$ to $44.5 \pm$ $16.4 \mathrm{ng} / \mathrm{ml}$, and the difference was statistically significant ( $\mathrm{p}<0.001)$ (fig. 1).

Serum calcium levels were similar at baseline and after 1 month of vitamin D therapy $(9.7 \pm 0.36$ vs. $9.8 \pm 0.61$, $\mathrm{p}=0.42)$. The PTH levels decrease after vitamin $\mathrm{D}$ treatment from $37.5 \pm 17.0$ to $26.7 \pm 14.3 \mathrm{mg} / \mathrm{dl}(\mathrm{p}<0.001)$.

Those with high BMI (z-scores) and increased serum ALP levels showed less benefit from vitamin D therapy than children with lower BMI and serum ALP levels ( $\mathrm{p}=$ $0.018, \mathrm{p}=0.011$, respectively).

The baseline and posttherapy levels of all biochemical parameters of the children with growing pains are given in table 2 . In children with growing pains, the intensity of pain showed no correlation with the basal $25(\mathrm{OH}) \mathrm{D}$, PTH and ALP levels or the BMI z-score.

Following vitamin D supplementation, the mean pain VAS score decreased from $6.8 \pm 1.9$ to $2.9 \pm 2.5 \mathrm{~cm}$. A significant reduction in pain intensity was observed at the after 3 months of vitamin $\mathrm{D}$ therapy (mean reduction $-3.8 \pm 2.1, \mathrm{r}=17.9, \mathrm{p}<0.001$; fig. 2). Children with a higher vitamin $\mathrm{D}$ level following treatment did not show greater reductions in their pain scores. In total, 31 (26.0\%) children with growing pains had no pain at the third month of vitamin D supplementation and 9 (7.5\%) had 
Table 2. Study parameters of the children with growing pains: mean change of parameters before and after a single oral dose of $25(\mathrm{OH}) \mathrm{D}$

\begin{tabular}{lccr}
\hline & Before therapy & After therapy & p value \\
\hline $25(\mathrm{OH}) \mathrm{D}, \mathrm{ng} / \mathrm{ml}$ & $13.4 \pm 7.2(<4-54.4)$ & $44.5 \pm 16.4(20.2-75.1)$ & $<0.05$ \\
Calcium, mg/dl & $9.7 \pm 0.3(8.8-10.5)$ & $9.8 \pm 0.5(9.1-10.6)$ & 0.43 \\
PTH, mg/dl & $37.5 \pm 17(17.7-82.3)$ & $26.7 \pm 14.3(15.2-56.7)$ & $<0.05$ \\
VAS, cm & $6.8 \pm 1.9(4-10)$ & $2.9 \pm 2.5(0-10)$ & $<0.05$ \\
Phosphate & $4.8 \pm 0.5(3.4-5.8)$ & & \\
ALP & $203.6 \pm 58.1(84-403)$ & & \\
CK & $105.8 \pm 38.5(34-251)$ & & \\
CRP & $0.15 \pm 0.17(0-0.9)$ & & \\
ESR & $11.7 \pm 5.4(3-28)$ & & \\
\hline
\end{tabular}

The data are expressed as mean values $\pm \mathrm{SD}$ (range). A paired Student's t test was used for statistical analysis $(\mathrm{p}<0.05) . \mathrm{CK}=$ Creatinine kinase; $\mathrm{CRP}=\mathrm{C}$-reactive protein; $\mathrm{ESR}=$ erythrocyte sedimentation rate.

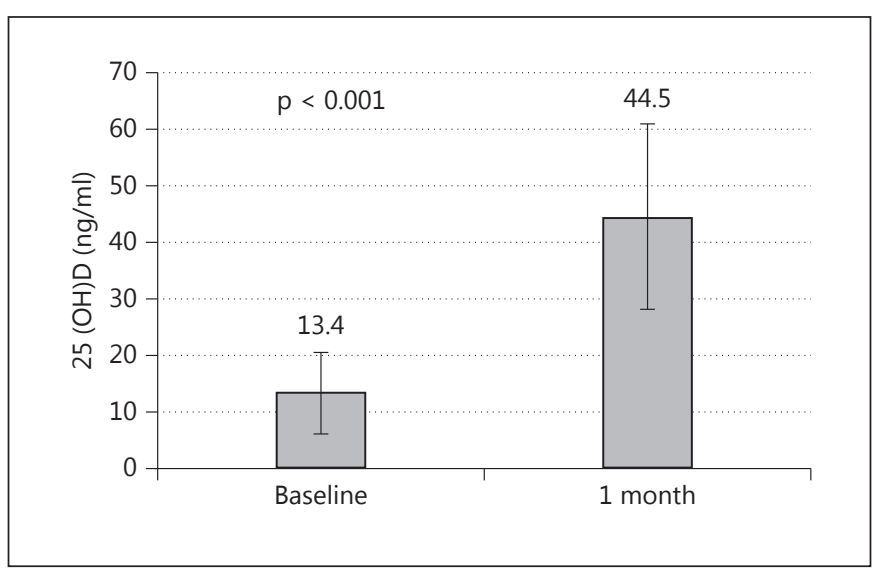

Fig. 1. 25(OH)D levels observed at the baseline and after 1 month of supplementation of vitamin $\mathrm{D}$ in the study group. The data are expressed as mean values. $\Delta$ difference: $33.24 \pm 16.5$. A paired Student's $\mathrm{t}$ test was used for statistical analysis. $\mathrm{p}<0.05$.

no change in the intensity of pain, despite a normalization of $25(\mathrm{OH}) \mathrm{D}$ levels. No significant difference was observed in the vitamin $\mathrm{D}$ levels of children whose pain resolved after vitamin treatment or in those with no change in pain intensity $(\mathrm{p}=0.092)$.

No adverse events related to vitamin $\mathrm{D}$ treatment were observed. After 1 month of vitamin D supplementation, the maximum serum $25(\mathrm{OH}) \mathrm{D}$ level was $75.1 \mathrm{ng} / \mathrm{ml}$ and the maximum serum calcium level was $10.6 \mathrm{mg} / \mathrm{dl}$ (both within the reference range). Four patients had an increased urine calcium-creatinine ratio. These children were further evaluated with renal ultrasonography, and no pathological findings were detected.

Outcome of Vitamin D Treatment in Children with Growing Pains

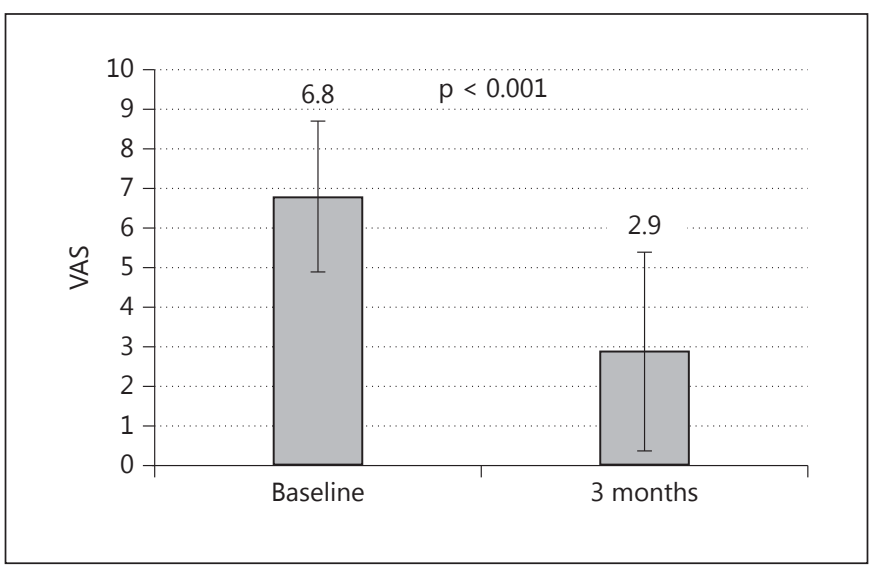

Fig. 2. VAS of the children with growing pains at the baseline and after 3 months. The data are expressed as mean values. $\Delta$ difference: $-3.8 \pm 2.1$. A paired Student's $t$ test was used for statistical analysis. $\mathrm{p}<0.05$.

\section{Discussion}

In this study, we found that vitamin D insufficiency and deficiency is a very common health problem among children in Istanbul. We showed that $86.6 \%$ of children with growing pains had hypovitaminosis D. Hypovitaminosis $\mathrm{D}$ is reported to be within the range of 70 90\% among healthy children and adolescents in Korea and Italy $[17,18]$. In China, in winter and spring, $>50 \%$ of school-aged children and adolescents reportedly have a vitamin D deficiency; in winter, $100 \%$ of adolescents and $93.7 \%$ of school-aged children were found to have vitamin D insufficiency in another study [19]. Turkey is a sunny country where vitamin $\mathrm{D}$ deficiency has been 
thought to be unusual. However, the reported prevalence of hypovitaminosis D here is $40-65 \%[12,13]$.

Studies investigating the prevalence of vitamin D deficiency in children with leg pains are limited $[20,21]$. In 2011, Qamar et al. [20] demonstrated a relationship between growing pains and vitamin D deficiency, but they did not aim to assess the effect of vitamin $\mathrm{D}$ therapy on pain resolution. They showed that $94 \%$ of children with growing pains had hypovitaminosis $\mathrm{D}$ and that $72 \%$ of them had vitamin D deficiency. A total of $26 \%$ of patients in their study population had hypocalcemia. Only 2 children had hypocalcaemia in our study. Morandi et al. [21] evaluated 33 children with growing pains. They found a mean 25(OH)D level of $15.0 \pm 6.9 \mathrm{ng} / \mathrm{ml}$. They found that vitamin $\mathrm{D}$ supplementation led to a significant increase in the $25(\mathrm{OH}) \mathrm{D}$ level that was associated with a significant decrease in pain intensity. These results are in agreement with our findings.

We found that the dark-skinned children had a lower $25(\mathrm{OH}) \mathrm{D}$ level than the fair-skinned children. Skin color is one of the major determinants of vitamin D status because a given amount of sun exposure produces less vitamin D in darker skin than in lighter skin [22]. The concentrations of melanin in skin regulate how much UV-B penetrates to reach the epidermal layers with the highest concentrations of 7-dehydrocholesterol. A high melanin concentration can cause decreased vitamin $\mathrm{D}$ synthesis by preventing UV-B from reaching the stratum basale and spinosum of the epidermis. Skin pigmentation determines the duration of sun exposure necessary to achieve a certain concentration of vitamin D. Dark-skinned people require a longer duration of sun exposure than fairskinned people for a similar response [22].

Growing pains are usually believed to be associated with nocturnal growth. Nevertheless, the term 'growing pains' is a misnomer because most affected children are at an age of relatively slower growth. We observed no clutter regarding the age distribution of the subjects in this study. The causative factors of growing pains remain unclear. Many theories have been proposed to explain the causes of growing pains, including muscular fatigue (an overuse response) in the affected extremity, anatomic problems, emotional or psychological distress, a lower pain threshold, decreased bone strength [23], altered vascular perfusion and joint hypermobility [24]. We hypothesized that hypovitaminosis D may have a role in the pathogenesis of growing pains, and that vitamin D supplementation might affect the bone and muscle status and decrease intensity of pain in children experiencing these pains. After vitamin D supplementation, we observed a significant reduction in pain intensity in children with growing pains accompanied by decreased PTH levels; this could be attributed to a greater amount of mineralized cortical bone.

Children with vitamin D deficiency are at greater risk for stunted growth. Usually, however, vitamin D deficiency is more commonly observed in obese children. We found that although all parameters were within the normal percentile ranges, children with growing pains had relatively low heights, weights and BMI z-scores compared with their peers. The main role of vitamin $\mathrm{D}$ is considered to be the regulation of calcium and phosphate metabolism. Recent studies have suggested that both the muscles and the components of the nervous system are target organs for vitamin D. Researchers have shown that vitamin D receptors are present in skeletal muscle cells [25]. Nonspecific musculoskeletal pains in adults are reportedly associated with decreased 25(OH)D levels, and improvement in pain has been attained with vitamin D therapy [26]. Warner and Arnspiger [27] reported that of 220 adults with diffuse musculoskeletal pain, only 22 showed a significant improvement with vitamin D therapy. Wepner et al. [28] investigated the effect of vitamin $D$ on patients with fibromyalgia using a VAS. A marked reduction in pain intensity was noted during the treatment period.

We believe that our study is the first to examine the effect of vitamin D treatment in children with growing pains using a VAS. Wehby et al. [29] used a VAS to measure health-related quality of life in children with oral clefts. Dhanani et al. [30] used a VAS to determine the difference in pain associated with changes in quality of life in children with rheumatic disease. The authors concluded that the VAS can be accepted as a valid and reliable method of assessing pain in the pediatric population, especially when children are adequately educated to use it correctly.

In this study, the 25(OH)D levels were measured by electrochemiluminescence enzyme immunoassay. Most immunoassay methods also measure $24,25(\mathrm{OH})_{2}$ vitamin $\mathrm{D}$ and its polar metabolites. They generally overestimate the vitamin D level by approximately $10-20 \%$. This might have led to an underestimation of the vitamin D insufficiency in both groups. High-performance liquid chromatography or tandem mass spectroscopy have been reported as the gold standards for vitamin D assays; however, these methods are time-consuming and expensive, which prohibited their use in our study. There is no consensus regarding the definition of the vitamin $\mathrm{D}$ status in children. We defined vitamin $\mathrm{D}$ deficiency as $<10 \mathrm{ng} / \mathrm{ml} \mathrm{ac-}$ cording to the American Academy of Pediatrics Com- 
mittee on Nutrition [16]. This may have led to an underestimation of the vitamin D deficiency. Vitamin D replacement therapy is necessary for children presenting with low vitamin $\mathrm{D}$ levels. A variety of dosing schemes are used: in children $>12$ months old, 2,000 IU/day for 6 weeks or 50,000 IU per week for 6 weeks followed by maintenance dosing of 600-1,000 IU/day. Another recommendation is (stoss therapy) $2.5-15.0 \mathrm{mg}$ or 100,000 600,000 IU of vitamin D as a single oral dose. We preferred stoss therapy, in order to guarantee the intake of a full dose.

After the vitamin D supplementation, we observed a significant increase in 25(OH)D levels and a significant reduction in pain intensity in children with growing pains. We could not perform a randomized controlled study because most of the children $(86.6 \%)$ had vitamin $\mathrm{D}$ deficiency or insufficiency, and it would have been unethical to withhold the vitamin D therapy. However, future randomized controlled studies will supply more data about the effectiveness of vitamin D therapy in children with growing pains. After 3 months of vitamin D therapy, we detected a significant reduction in pain intensity among the children with growing pains. This suggests that vitamin D might improve the symptoms of this con- dition. However, alternative reasons for improvement cannot be ruled out. To resolve this, a well-designed randomized controlled trial is warranted.

\section{Conclusion}

In this study, there was a high prevalence of hypovitaminosis D in children with growing pains. Vitamin D supplementation significantly increased the $25(\mathrm{OH}) \mathrm{D}$ levels and caused a significant reduction in pain intensity in children with growing pains. This finding could suggest that vitamin $\mathrm{D}$ therapy may reduce the pain intensity among children with growing pains. Monitoring $25(\mathrm{OH}) \mathrm{D}$ levels and, when indicated, supplementing nutritional calcium and oral vitamin D could help to resolve growing pains. A reduction in pain can lead to an improved quality of life. Further studies should address this topic.

\section{Acknowledgements}

The authors of this paper would like to thank the mothers and children who participated in the study.

\section{References}

1 Uziel Y, Hashkes PJ: Growing pains in children. Harefuah 2008;147:809-811.

- 2 Evans AM, Scutter SD: Prevalence of 'growing pains' in young children. J Pediatr 2004; 145 : 255-258.

3 Mohanta MP: Growing pains: practitioners' dilemma. Indian Pediatr 2014;51:379-383.

4 Goodyear-Smith F, Arroll B: Growing pains. BMJ 2006;333:456-457.

5 Asadi-Pooya AA, Bordbar MR: Are laboratory tests necessary in making the diagnosis of limb pains typical for growing pains in children? Pediatr Int 2007;49:833-835.

6 Evans AM: Growing pains: contemporary knowledge and recommended practice. J Foot Ankle Res 2008;28:4.

7 Palermo NE, Holick MF: Vitamin D, bone health, and other health benefits in pediatric patients. J Pediatr Rehabil Med 2014;7:179_ 192.

8 Pludowski P, Holick MF, Pilz S, et al: Vitamin $\mathrm{D}$ effects on musculoskeletal health, immunity, autoimmunity, cardiovascular disease, cancer, fertility, pregnancy, dementia and mortality - a review of recent evidence. Autoimmun Rev 2013;12:976-989.
9 Vujosevic S, Borozan S, Radojevic N, et al: Relationship between 25 -hydroxyvitamin $\mathrm{D}$ and newly diagnosed type 2 diabetes mellitus in postmenopausal women with osteoporosis. Med Princ Pract 2014;23:229-233.

10 de Rezende Pena C, Grillo LP, das Chagas Medeiros MM: Evaluation of 25-hydroxyvitamin $\mathrm{D}$ serum levels in patients with fibromyalgia. J Clin Rheumatol 2010;16:365-369.

11 Tandeter H, Grynbaum M, Zuili I, et al: Serum $25-\mathrm{OH}$ vitamin $\mathrm{D}$ levels in patients with fibromyalgia. Isr Med Assoc J 2009;11:339342.

12 Andıran N, Celik N, Akca H, et al: Vitamin D deficiency in children and adolescents. J Clin Res Pediatr Endocrinol 2012;4:25-29.

13 Hatun S, Islam O, Cizmecioglu F, et al: Subclinical vitamin $\mathrm{D}$ deficiency is increased in adolescent girls who wear concealing clothing. J Nutr 2005; 135:218-222.

14 Roberts WE: Skin type classification systems old and new. Dermatol Clin 2009;27:529-533.

15 Davies JH, Shaws NZ: Preventable but no strategy: vitamin $\mathrm{D}$ deficiency in the UK. Arch Dis Child 201;96:614-615.

16 Misra M, Pacaud D, Petryk A, et al: Vitamin $D$ deficiency in children and its management: review of current knowledge and recommendations. Pediatrics 2008;122:398-417.
17 Han SW, Kang HR, Kim HG, et al: Subclinical vitamin $\mathrm{D}$ insufficiency in Korean schoolaged children. Pediatr Gastroenterol Hepatol Nutr 2013;16:254-260.

18 Vierucci F, Del Pistoia M, Fanos M, et al: Vitamin D status and predictors of hypovitaminosis D in Italian children and adolescents: a cross-sectional study. Ital J Pediatr 2014;5: 54.

19 Zhu Z, Zhan J, Shao J, et al: High prevalence of vitamin $D$ deficiency among children aged 1 month to 16 years in Hangzhou, China. BMC Public Health 2012;14:126.

20 Qamar S, Akbani S, Shamim S, et al: Vitamin D levels in children with growing pains. J Coll Physicians Surg Pak 2011;21:284-287.

21 Morandi G, Maines E, Piona C, et al: Significant association among growing pains, vitamin D supplementation, and bone mineral status: results from a pilot cohort study. J Bone Miner Metab 2015;33:201-206.

22 Holick MF: Bioavailability of vitamin D and its metabolites in black and white adults. $\mathrm{N}$ Engl J Med 2013;369:2047-2048.

23 Friedland O, Hashkes PJ, Jaber L, et al: Decreased bone speed of sound in children with growing pains measured by quantitative ultrasound. J Rheumatol 2005;32:1354-1357. 
24 Hashkes PJ, Gorenberg M, Oren V, et al: 'Growing pains' in children are not associated with changes in vascular perfusion patterns in painful regions. Clin Rheumatol 2005;24: 342-345.

25 Godar DE, Pope SJ, Grant WB, et al: Solar UV doses of adult Americans and vitamin D(3) production. Dermatoendocrinology 2011;3: 243-250.

26 Le Goaziou MF, Kellou N, Flori M, et al: Vitamin D supplementation for diffuse muscu- loskeletal pain: results of a before-and-after study. Eur J Gen Pract 2014;20:3-9.

27 Warner AE, Arnspiger SA : Diffuse musculoskeletal pain is not associated with low vitamin D levels or improved by treatment with vitamin D. J Clin Rheumatol 2008;14: 12-16.

28 Wepner F, Scheuer R, Schuetz-Wieser B, et al: Effects of vitamin D on patients with fibromyalgia syndrome: a randomized placebo-controlled trial. Pain 2014;155:261-268.
29 Wehby GL, Naderi H, Robbins JM, et al: Comparing the Visual Analogue Scale and the Pediatric Quality of Life Inventory for measuring health-related quality of life in children with oral clefts. Int J Environ Res Public Health 2014;16:4280-4291.

30 Dhanani S, Quenneville J, Perron M, et al: Minimal difference in pain associated with change in quality of life in children with rheumatic disease. Arthritis Rheum 2002;15:501505 . 